\section{Relació entre l'anàlisi del sentiment, els resultats acadèmics i l'abandonament als entorns virtuals \\ d'aprenentatge.}

UTE. Revista de Ciències de l'Educació

2019 núm. 1. Pàg. 19-32

ISSN 1135-1438. EISSN 2385-4731

http://revistes.publicacionsurv.cat/index.php/ute

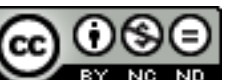

DOI: https://doi.org/10.17345/ute.2019.1

\author{
Adolf Maria Iglesias i Estradé
}

Rebut: 24/6/2019 Acceptat: 09/7/2019

\begin{abstract}
Resum
Les relacions entre els agents educatius s'han desplaçat fins a posar l'alumne al centre del procés d'ensenyament-aprenentatge (E-A). En aquest sentit, els sentiments -l'anàlisi dels quals era, fins ara, molt lenta i qualitativa - han esdevingut sempre un mitjà d'expressió important durant aquest procés. El professor ha de ser capaç d'identificar el ritme i l'evolució del coneixement del seu alumne per a adaptar els continguts però també ha de poder identificar el seu estat emocional. Els avantatges que presenten els entorns virtuals d'aprenentatge (EVA) han permès la seva implantació en moltes institucions educatives. Això no obstant, els estudiants en aquests entorns se senten frustrats per la sensació d'aillament fruit de la manca de relació pròxima amb altres persones. Aquest sentiment pot tenir conseqüències en forma d'abandonament $O$ de baix rendiment. Els entorns virtuals, a més, eliminen molts dels factors que s'utilitzen per a copsar l'estat emocional de les persones. Moltes vegades, l'únic canal de transmissió és la paraula escrita. L'anàlisi del sentiment és una tècnica que es basa en l'aplicació de la intel-ligència artificial als textos en llenguatge natural per a classificar els textos segons les emocions expressades, molt utilitzada amb finalitats d'anàlisi de mercats però amb molt poc desenvolupament als EVA. En aquest treball es demostra que existeix una relació entre les emocions expressades per l'alumnat en els missatges escrits i la tassa d'abandonament dels estudis en un EVA. El resultat assolit ha de servir per a què els tutors puguin quantificar l'estat i l'evolució emocional del grup de forma automàtica per a poder intervenir-hi i afavorir la millora dels sentiments a l'aula amb la finalitat de reduir-ne l'abandonament.
\end{abstract}

Paraules clau: entorns virtuals d'aprenentatge, anàlisi del sentiment, abandonament, resultats acadèmics.

\begin{abstract}
The relationships between educational agents have moved to place the student at the center of the teaching-learning process. In this way, feelings - whose analysis was, until now, very slow and qualitative- have always become an important means of expression during this process. Teachers must be able to identify the rhythm and evolution of the knowledge of their students to adapt the contents
\end{abstract}


but also must be able to identify his emotional state. The advantages of virtual learning environments (VLE) have leaded to implement them in many educational institutions. However, students may feel frustrated by the feeling of isolation resulting from the lack of close relationships with other people. That fact can produce education drop out or low performance. Virtual environments have also eliminated many of the factors that are used to capture the emotional state of people. Sometime, the only transmission channel is the written word. The analysis of sentiment is a technique that based on the application of artificial intelligence to texts in natural language is able to classify texts according to the emotions expressed, deeply used for marketing analysis but slightly developed for VLE. In this work it is shown that there is a relationship between the emotions expressed by the students in the written messages and the drop out of the studies in a VLE. The result achieved can help tutors to automatically quantify the emotional state and its evolution so he can intervene and favor the improvement of the expressed feeling of the classroom in order to reduce drop out.

Keywords: Virtual learning environment, sentiment analysis, drop out, student performance

La irrupció de les noves tecnologies a la nostra realitat quotidiana ha permès que l'aprenentatge s'hagi pogut desplaçar més enllà de les aules físiques i s'hagi ampliat a d'altres entorns promoguts per les comunicacions, els ordinadors personals $\mathrm{i}$ els dispositius mòbils. Els entorns virtuals d'aprenentatge (EVA) han estat la resposta que les tecnologies de la informació i la comunicació (TIC) han ofert a l'ensenyament per a promoure un aprenentatge asíncron i deslocalitzat entre els docents i els discents.

Un dels principals problemes dels estudis en línia és la frustració de l'estudiant que el pot conduir a l'abandonament de la seva formació (Conrad, 2002). En aquest sentit, "la resposta que [el docent] doni als estudiants, la seua presència a l'aula, la claredat en les indicacions, la proximitat i la flexibilitat [i] la interacció i la col-laboració" (Borges, 2005, p.3) poden prevenir-la o reduir-la. S'ha demostrat que una interacció del professorat en el que s'ha anomenat Computer Mediated Comunicacion (CMC) "senzilla [...], absent d'estructura i lideratge, no és suficient. [És necessari] tenir una visió qualitativament més rica de la interacció." (D. Randy Garrison \& Cleveland-Innes, 2005). Anderson, Rourke, Garrison i Archer (2001) han desenvolupat un "marc conceptual per entendre, mesurar i millorar la funció important de "presència docent" dins d'un EVA que es basa en un "tres components crítics: la presència cognitiva, la presència social i la presència docent" (Anderson, 2004). Estudis més recents, com els de Garrison (2007) i Mckerlich, Riis, Anderson i Eastman (2011) confirmen i reforcen la importància per als estudiants de les diferents presències seguint els components crítics expressats adés. Igualment, Gilly (2000) desenvolupa un model per al tutor en línia que ella anomena e-moderador, el qual ha de ser capaç de facilitar l'accés dels estudiants a l'EVA així com proporcionar-los la motivació necessària, tot reforçant el que Anderson i col-legues (2001) anomenen la "presència social" del docent.

Com a conseqüència, se n'extreu que un dels factors per assolir un millor rendiment i reduir la tassa d'abandonament dels estudis en línia -on l'estudiant pot accedir a l'aula a través d'un dispositiu mòbil que disposi de connexió a Internet sense restriccions ni horàries ni geogràfiques, però també sense interacció ni directa ni immediata amb el tutor- rau en el rol del docent. És important que aquest pugui conèixer l'estat emocional dels alumnes. Aquesta informació es realitzarà a través de l'únic canal que els uneix: la comunicació telemàtica a través dels ordinadors, atès que la interacció que s'estableix als EVA entre docent i discent es fa mitjançant xats i fòrums virtuals on tothom s'expressa amb textos escrits.

La incorporació de la intel-ligència artificial (IA) en l'educació és una de les tendències més sòlides que es repeteixen als diferents informes de previsió sobre com evolucionarà l'ensenyament les properes dècades. (Consortium, 2017; EUCASE Review, 2018). Un dels camps de la IA que més ha crescut és 
l'aprenentatge automàtic (machine learning, en anglès) que es basa en desenvolupar agents que aprenen determinades habilitats de forma autònoma després d'un cert període d'entrenament dirigit. D'altra banda, la necessitat d'establir una interacció natural entre l'home i les màquines ha promogut també una disciplina que combina lingüística i informàtica: el processament del llenguatge natural. L'objectiu és poder-se comunicar amb els ordinadors amb el mateix codi amb el que ens comuniquem els humans entre nosaltres, amb les interpretacions per part dels receptors correctes de les diferents convencions naturals de estudiades per la pragmàtica. De la combinació d'ambdues disciplines sorgeixen agents capaços d'interpretar i entendre automàticament textos escrits en llenguatge natural.

L'evolució de la web dinàmica denominada 2.0 es basa en l'eclosió i posterior aprofitament de les xarxes socials a la web, de forma que els usuaris han passat a ser també autors de continguts. Les empreses de comerç electrònic es van trobar que els clients es podien comunicar directament entre ells $i$ intercanviar opinions sobre els productes o els serveis que s'oferien. L'aprenentatge automàtic basat en el processament del llenguatge natural va ser la tecnologia que les empreses van utilitzar per a fer un buidatge de les opinions i conèixer què s'hi expressaven (Yanagimoto, Shimada i Yoshimura, 2013). Així mateix, es va començar a emprar aquesta tecnologia per a detectar no només què opinaven els usuaris sinó també quin era el sentiment que denotaven les intervencions. De l'aprofitament de l'aprenentatge automàtic basat en el processat natural del llenguatge se' $n$ va anomenar anàlisi del sentiment (sentiment analysis, en anglès) (Pang \& Lee, 2009).

L'origen de l'anàlisi del sentiment es troba en l'anomenada mineria d'opinions (opinion minning, en anglès) que va sorgir per l'interès de conèixer les opinions expressades pels usuaris de pàgines web on s'expressaven opinions de determinades pel-lícules (Pang, Lee, \& Vaithyanathan, 2002; Turney, 2001). La possibilitat de poder copsar automàticament l'opinió de milers d'usuaris al voltant de determinats productes va generar molt d'interès per part de les empreses i les marques publicitàries. Aleshores, amb la intenció de poder conèixer millor què opinen els consumidors, la mineria d'opinions va donar pas a I'anàlisi del sentiment.

L'objectiu d'aquesta recerca serà determinar la correlació entre les emocions, expressades en els missatges de l'EVA i quantificades a través de l'anàlisi del sentiment, i la tassa d'abandonament de la mostra d'estudiants avaluada. Aleshores, i en el cas que existeixi alguna relació significativa entre les variables analitzades, el coneixement per part del tutor dels sentiments expressats pels estudiants a través dels diferents canals de comunicació telemàtica li haurà de permetre adequar el missatge i millorar d'aquesta forma la seva "presència social", amb la finalitat d'evitar la desmotivació dels participants.

Als darrers anys s'han dut a terme nombrosos estudis que han fet recerca al voltant de quins son els factors que motiven la persistència o provoquen l'abandonament dels estudis. En aquest apartat en farem una revisió tot centrant l'interès en els cursos d'ensenyament a distància. En un estudi realitzat per Gütl, Rizzardini, Chang i Morales (2014) es detecta que els índexs de finalització d'un dels casos concrets de formació a distància, els MOOC (cursos massius de formació en línia), és inferior al 10\%. Els motius que condueixen a aquests resultats tan preocupants són classificats en diferents dimensions: motius personals, motius acadèmics, manca de suport i motivats per l'entorn d'aprenentatge. De les dues darreres categories, destaquen la manca de suport per part de familiars, companys o empleats, la manca de retroalimentació de les avaluacions i la poca interacció amb la resta de companys i amb el professorat.

Tot i que "l'abandonament és un fenomen multi-factor, en el sentit que les raons que hi ha darrere [son conseqüència] de la interacció d'un ampli conjunt de factors personals i contextuals" (Rodríguez-Gómez, Feixas, Gairín i Luís Muñoz, 2012, p.1427), "la capacitat de tractar amb èxit la multitud d'estrès emocionals trobats en la vida universitària [sembla] ser un factor important en la retenció dels estudiants" (Pritchard i Wilson, 2003, p.25). 
Yang, Sinha, Adamson, \& Rosé (2013) suggereixen que el comportament dels estudiants en el fòrum de debat podria predir l'abandonament, i conclouen amb la necessitat de comprendre com es formen els vincles en els fòrums en línia, des de l'inici. Això, segons aquests autors, és clau per a què els alumnes puguin crear vincles intensos i es sentin integrats en el curs.

Finalment, García-Mangas (2018) ha desenvolupat una recerca molt propera a aquest treball amb el focus posat en la mateixa població: els estudiants de formació professional dels ensenyaments en línia. Les investigacions de García-Mangas conclouen que "encara que no s'han trobat un factors estadísticament significatius, sí que es poden observar unes tendències a aquests factors [:] D'una banda, el disseny de les activitats, i d'altra, la comunicació i el feedback de l'alumne ( $p$. 67)". En referència a aquest darrer factor, remarca "la importància de fugir de missatges generals i impersonals que generen una sensació de soledat i poca importància dels alumnes, sinó utilitzar, en la mesura del possible, missatges que demostrin que s'atén, ja sigui individualment o en grup, a dubtes i problemes concrets que sorgeixen al grup (p.68)".

Dels estudis exposats fins al moment se n'extreu la necessitat de conèixer els sentiments tant individuals com grupals dels alumnes que participen a la formació a distància per a poder establir una comunicació empàtica $\mathrm{i}$ individualitzada que afavoreixi el sentiment de pertinença per part de l'estudiant tot millorant-ne la seva satisfacció i la seva confiança i finalment reduir l'abandonament en aquests contextos.

D'altra banda, no existeix una literatura encara massa extensa al voltant de l'ús de l'anàlisi del sentiment com a eina de coneixement dels estudiants als aprenentatges en línia. Munezero, Montero, Mozgovoy i Sutinen (2013) "han explorat l'anàlisi automàtica i el seguiment de les emocions en els diaris d'aprenentatge dels estudiants [...] com un sistema d'ajuda per millorar els mètodes d'ensenyament i els comentaris dels instructors i servir com a mitjà de reflexió per als estudiants. (p. 6)". Al seu treball han desenvolupat un mètode molt interessant que extreu diferents estats emocionals amb diferents nivells $i$ polaritats que resulta en un diagrama circular que afavoreix la comprensió dels resultats amb una gràfica molt visual.

Ezen-Can, Boyer, Kellogg i Booth (2015) després d'analitzar com aprenen els estudiants als MOOC indiquen que "és possible aplicar un marc de modelització no supervisat desenvolupat per converses síncrones i discussions asíncrones [...] tot i que importants diferències en l'estructura [dels textos] suggereixen que és necessari realitzar un pas addicional de modelatge temàtic per formar models més interpretables i cohesius (p. 1)". D'altra banda, hi ha també estudis que exploren l'anàlisi del sentiment no directament sobre els fòrums ni els canals formals de comunicació sinó que ho fan indirectament a través de les xarxes socials (Altrabsheh i colllegues, 2013; Nielsen, 2011; Ortigosa, Martín i Carro, 2014).

La població amb la que s'ha realitzat la recerca són alumnes de cicle formatiu de grau superior en modalitat telemàtica. L'estudi s'ha basat en els estudis de l'Institut Obert de Catalunya (IOC). Per al treball s'ha utilitzat el mòdul professional de Formació i Orientació Laboral (FOL). El mòdul "Formació i orientació laboral" és un mòdul transversal que s'estudia a tots els cicles professionals, i que té l'objectiu fonamental d'iniciar el futur tècnic professional en el món del treball, oferint-li una sèrie de recursos que li han de permetre l'accés al mercat laboral i la planificació del seu futur professional. Està distribuït en dues unitats formatives (UF): UF1, Incorporació al treball, de 66 hores, i UF2, Prevenció de riscos laborals, de 33 hores. Segons resa el pla de treball de la matèria, la qualificació final del mòdul (QFM) serà el resultat de la mitjana de les qualificacions de les diferents UF d'acord amb la següent ponderació:

$$
\text { QFM= QUF1 x 0,665 + QUF2 × 0,335. }
$$


S'ha escollit aquest mòdul perquè és una matèria transversal que s'imparteix a tots els cicles formatius $i$ que, en conseqüència, han de cursar simultàniament durant cada semestre tots els estudiants de l'IOC de grau superior. Això permet comptar amb 10 aules, tutoritzades cadascuna per un docent diferent, amb una norantena d'alumnes en cada grup-classe. Concretament, la distribució de la població és la que segueix:

Taula 1: Distribució dels alumnes per aules

\begin{tabular}{cc}
\hline Aula & Nombre \\
\hline AULA 01 & 88 \\
AULA 02 & 88 \\
AULA 03 & 87 \\
AULA 04 & 88 \\
AULA 05 & 88 \\
AULA 06 & 87 \\
AULA 07 & 92 \\
AULA 08 & 85 \\
AULA 09 & 89 \\
AULA 10 & 98 \\
\hline
\end{tabular}

Per a extreure l'expressió dels sentiments dels alumnes en cada grup-classe s'utilitzaran les seves aportacions al fòrum de debat que existeix en cadascuna de les aules de l'entorn virtual d'aprenentatge, mitjançant l'anàlisi del sentiment. Una variable de la investigació, "expressió dels sentiments dels alumnes" (variable que a priori semblaria difícilment objectivable), ens arribarà operacionalitzada a través d'algorismes computacionals que l'extrauran dels textos escrits i obtindran la polaritat del sentiment de forma quantitativa. Això ens permetrà mesurar-la correctament ${ }^{\mathrm{a}}$. Les altres variables s'extrauran de l'expedient acadèmic que apareix en cadascuna de les aules del mòdul professional.

La forma de classificació que s'utilitzarà per a determinar el sentiment expressat pels alumnes durant el fòrum serà una màquina de vector de suport (SVM de l'anglès Support Vector Machine). Les SVM pertanyen a la categoria dels classificadors lineals ja que produeixen separadors lineals o hiperplans en l'espai original o en un espai transformat. S'entén per espai transformat a la conversió d'un espai original on no és possible establir la classificació en un espai caracteritzat de forma que la classificació esdevingui possible. La utilització de les SVM a l'anàlisi del sentiment requerirà una transformació de l'espai on els textos que cal classificar es convertiran en valors numèrics a partir de diferents codificacions de funcions categòriques. Per a la investigació s'usarà una codificació denominada one hot encoding (codificació en calent). L'entrada a aquest procés ha de ser una matriu de nombres enters o cadenes, que denotin els valors assumits per funcions categòriques (discretes). La determinació del plànol de separació als espais transformats es fa en base a unes funcions denominades nucli o kernel que en el nostre cas serà lineal. Les aules de la 1 a la 4 s'utilitzaran per a l'entrenament i el test de la rutina d'aprenentatge automàtic. La resta de les aules serviran per a respondre les preguntes de la investigació de la recerca.

Per a l'índex d'abandonament s'han comptabilitzat els alumnes que no han finalitzat les unitats formatives corresponent. En cas d'existència de valors divergents, s'ha usat el valor menor d'ambdós perquè s'ha considerat que la diferència provenia d'estudiants que s'havien matriculat només d'una sola unitat formativa. Aleshores, la variable final ha estat la relació percentual entre els estudiants que no han

\footnotetext{
${ }^{a}$ Es tracta d'un procés que també ens permetria usar la variable del sentiment com a complement d'estudis qualitatius on es facin servir documents de text com entrevistes a alumnes, etc.
} 
finalitzat el semestre respecte el total dels alumnes participants de cada aula. Els valors obtinguts són els següents:

Taula 2: Índex d'abandonament

\begin{tabular}{ccc}
\hline Aula & Alumnes que & Índex \\
\hline AULA 05 & 13 & $14,94 \%$ \\
AULA 06 & 13 & $17,24 \%$ \\
AULA 07 & 18 & $19,57 \%$ \\
AULA 08 & 14 & $16,67 \%$ \\
AULA 09 & 21 & $25,00 \%$ \\
AULA 10 & 17 & $17,17 \%$ \\
\hline
\end{tabular}

Per mesurar el rendiment acadèmic es calcula la qualificació final del mòdul segons l'equació [Eq. 1]. Les qualificacions finals obtingudes són les següents:

Taula 3: Resultats acadèmics

\begin{tabular}{cccc}
\hline AULA & QUF & QUF & QFM \\
\hline AULA 05 & 3,59 & 4,56 & 3,91 \\
AULA 06 & 3,3 & 4,56 & 3,72 \\
AULA 07 & 3,22 & 4,41 & 3,62 \\
AULA 08 & 2,92 & 4,19 & 3,35 \\
AULA 09 & 3,77 & 4,97 & 4,17 \\
AULA 10 & 3,12 & 2,91 & 3,05 \\
\hline
\end{tabular}

\subsection{Instruments, tècniques utilitzades i procediments}

Per a l'operacionalització de la variable "expressió del sentiment" a partir de les aportacions dels alumnes al fòrum de debat de l'aula s'ha seguit el procés d'anàlisi del sentiment desenvolupat amb les rutines d'aprenentatge automàtic d'una màquina de vector de suport. El procés complet d'anàlisi del sentiment que s'ha seguit és el següent:

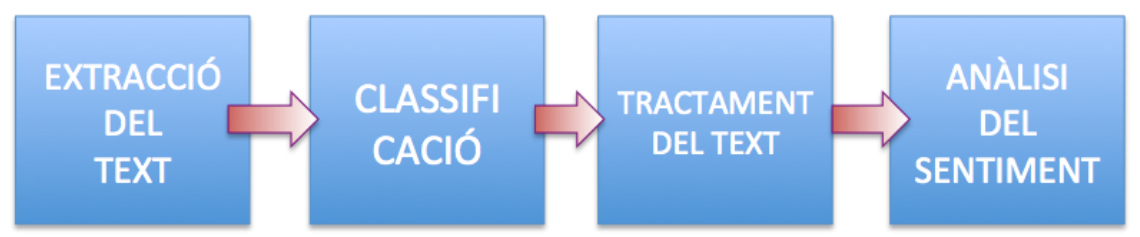

Figura 1: Diagrama de blocs dels procés d'anàlisi del sentiment

L'anàlisi del sentiment parteix dels comentaris que els alumnes expressen al fòrum de debat de cadascuna de les aules. Atès que l'Institut Obert de Catalunya utilitza la plataforma Moodle com a suport per a les seves matèries, el primer pas necessari era poder comptar amb aquest material. Inicialment, l'aspecte dels fòrums de debat és el següent: 


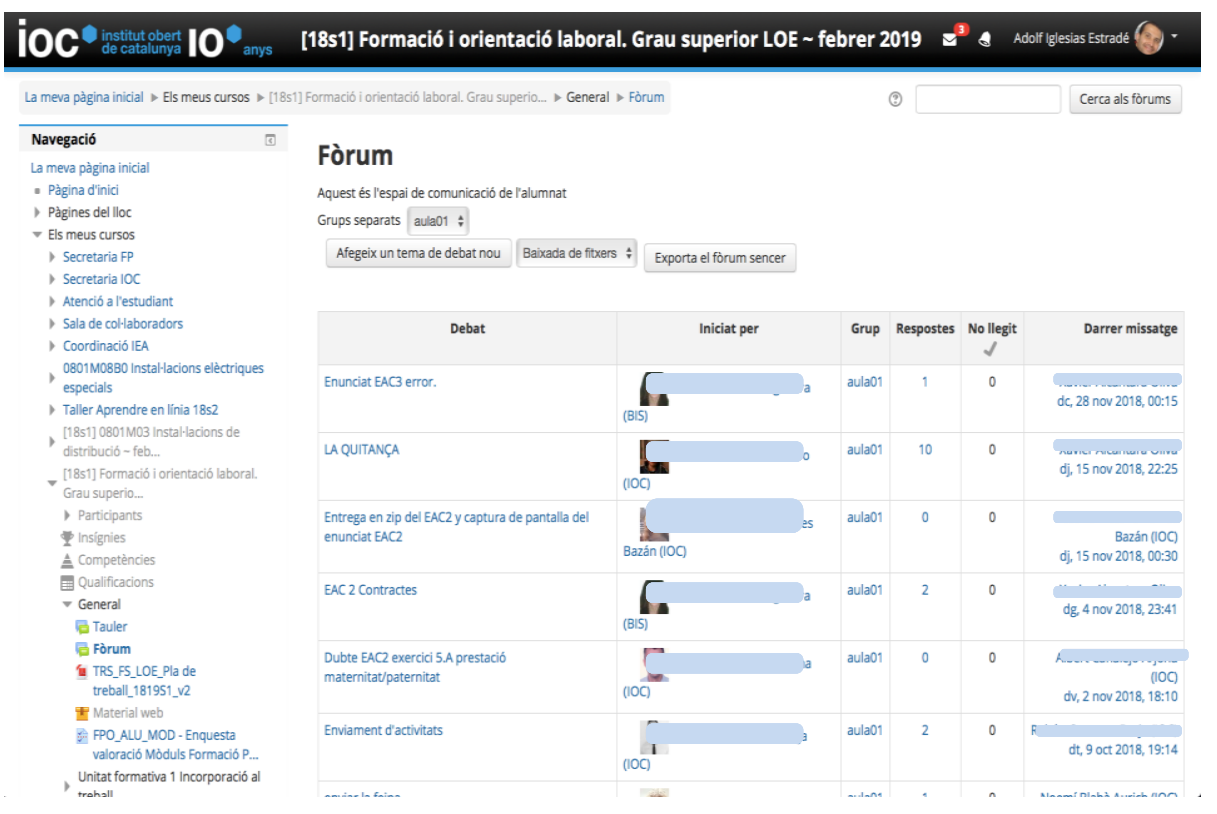

Figura 2: Fòrum de debat en una plataforma Moodle

Per a seleccionar i extreure només els fragments de text del fòrum va caldre desenvolupar una rutina en Python a partir de les funcions de la llibreria BeautifulSoup accessible des de l'entorn Spyder. El codi que es va utilitzar va ser html2text.py.

\subsection{Classificació dels missatges}

Per a entrenar la màquina és necessari tenir un conjunt de missatge classificats prèviament que s'utilitzaran per a què la màquina aprengui les característiques dels textos de caràcter positiu i les diferencii dels textos de caràcter negatiu. Atès que no existeix cap corpus textual basat en textos de caràcter acadèmic ha estat necessari crear-ne un ad hoc. Per a fer-lo s'han utilitzat els arxius de les aules 01, 02,03 i 04 i s'han classificat de forma manual organitzats en dos arxius nous: train-positive-final.txt i train-negative-final.txt. El procés de creació d'ambdós arxius s'ha basat en la lectura dels arxius forum.txt de les 4 aules esmentades amb la posterior classificació de cadascun dels missatges com a positiu o negatiu. El criteri que s'ha establert a l'hora de classificar els textos es detalla tot seguit:

1. S'han eliminat els missatges de presentació al fòrum. L'IOC proposa que a l'inici de cada semestre els participants d'una aula es presentin al fòrum amb la intenció de personalitzar la seva assistència al grup-classe. És un espai personal que permet als alumnes conèixer les cares noves i retrobar les velles, així com saber quelcom de caràcter personal del seu tutor. Malgrat tot, s'ha considerat que aquesta informació no forma part del procés d'aprenentatge i no s'ha inclòs en l'entrenament de la màquina.

2. S'han considerat com a positius els missatges amb un caràcter afirmatiu i expositiu; és a dir, aquells que informen amb caràcter objectiu o que responen els dubtes formulats amb oracions afirmatives.

3. S'han considerat com a negatius els missatges amb un caràcter interrogatiu i dubitatiu. En aquest grup s'hi inclouen, finalment, tots els textos interrogatius i/o els que denoten desorientació sobre algun dels aspectes del curs.

\subsection{Creació, entrenament $i$ test de la màquina}

Un cop ailllats els missatges del fòrum en un arxiu de text el pas següent és classificar quina és la valència del sentiment que apareix als missatges del fòrum, dada que s'usarà com a variable dependent que ha 
de servir per a cercar les correlacions amb la taxa d'abandonament i els resultats acadèmics. Per a ferho es desenvoluparà el codi denominat train-classifier.py.

Amb els arxius formats pels textos positius i negatius s'ha entrenat la màquina. Per a fer-ho, en primer lloc s'ha hagut de separar cada frase en els mots que la formen. Aleshores, s'ha creat una primera matriu de termes positius associats al tret positiu (identificat com a 'pos') i una segona matriu amb els termes negatius associats al seu torn al tret negatiu (identificat amb l'etiqueta 'neg'). Aquestes matrius s'han separat en dues parts: el $75 \%$ per a l'entrenament i el $25 \%$ per al test. Amb aquests paràmetres s'han entrenat la màquina i, posteriorment, s'ha testejat el seu funcionament.

\subsection{Anàlisi del sentiment}

Un cop s'ha creat i s'ha entrenat la màquina d'aprenentatge automàtic és el moment de fer la predicció dels resultats. Per a fer-ho, s'han obert els diferents arxius forum.txt de les aules sobre les quals es fa la investigació -això és, de la 05 a la 10 - i s'ha repetit el procés de separació dels missatges en paraules. La matriu resultant s'ha utilitzat com a paràmetre d'entrada a la funció de predicció de la llibreria Linear SVC que retorna una matriu amb el total de missatges positius i negatius detectats.

La relació entre els indicadors negatius i el total de missatges de l'aula s'ha usat com a variable directa per a determinar el sentiment de cadascun dels grups-classe expressats al fòrum de debat del curs.

\section{4.}

Amb la intenció de comprendre millor el comportament de les diferents variables s'aprofita la versatilitat de de les funcions que aporta JASP per a obtenir els resultats de l'estadística descriptiva de cadascuna d'elles.

Taula 4: Estadística descriptiva de les variables dependents

\begin{tabular}{cccc}
\multicolumn{4}{c}{ Estadística descriptiva } \\
\hline Valid & 6 & VD2: índex & VD3: resultats \\
Missing & 0 & 6 & 6 \\
Mean & 0.2670 & 0 & 0 \\
Std. Deviation & 0.1271 & 0.1843 & 3.637 \\
Minimum & 0.1618 & 0.0354 & 0.4003 \\
Maximum & 0.5000 & 0.1494 & 3.050 \\
\hline
\end{tabular}

És pertinent incloure, abans d'exposar els resultats finals de l'anàlisi del sentiment que s'ha obtingut en cadascuna de les diferents aules, quins han estat els indicadors de validesa que ha obtingut la màquina d'aprenentatge desenvolupada segons apareixen a la taula 7.

Taula 5: Indicadors de validesa de la màquina d'aprenentatge

\begin{tabular}{|l|l|} 
Exactitud & 0,7424 \\
Precisió & 0,7382
\end{tabular}




$$
\left|\begin{array}{l|l}
\text { Sensibilitat } & 0,8960 \\
\text { f1 } & 0,8006
\end{array}\right|
$$

S'observa que tots els indicadors tenen un valor elevat, entre el $70 \%$ i el $90 \%$, i que, per tant, els resultats generats per la màquina virtual són fiables.

Els resultats de l'anàlisi del sentiment que ha predit la màquina a partir dels missatges extrets del fòrum de debat de cadascuna de les aules són el que segueixen:

Taula 6: Anàlisi del sentiment de les aules del curs (VD1)

\begin{tabular}{cc}
\hline Aula & Anàlisi del \\
\hline AULA 05 & 0,1964 \\
AULA 06 & 0,1618 \\
AULA 07 & 0,2331 \\
AULA 08 & 0,3223 \\
AULA 09 & 0,5 \\
AULA 10 & 0,1884 \\
\hline
\end{tabular}

L'índex d'abandonament que s'ha extret del full de càlcul els trobem a la taula 2.

Els resultats de la correlació entre les variables dependents que s'han obtingut als apartats anteriors són els següents, exposats, en primer lloc, en forma de matriu de correlació.

Taula 7: Matriu de correlacions

Correlacions de Pearson

\begin{tabular}{cccc}
\hline & & $\begin{array}{c}\text { VD1: expressió del } \\
\text { sentiment }\end{array}$ & VD2: índex d'abandonament VD3: resultats acadèmics \\
\hline VD1expressió del & Pearson's $r$ & - & \\
sentiment & p-value & - & - \\
VD2: índex & Pearson's $r$ & 0.828 & - \\
d'abandonament & p-value & $0.042^{*}$ & 0.519 \\
VD3: resultats acadèmics & Pearson's r & 0.498 & 0.292 \\
& p-value & 0.315 & \\
\hline
\end{tabular}

${ }^{*} p<.05,{ }^{* *} p<.01,{ }^{* * *} p<.001$

Dels resultats anteriors, s'observa que existeix una correlació significativa i positiva $(p=0,042)$ entre els sentiments dels l'alumne expressat als fòrum de debat de l'aula i l'índex d'abandonament,

En primer discutirem la correlació entre l'anàlisi del sentiment expressat pels alumnes al fòrum de debat i l'índex d'abandonament dels estudis, que ha estat positiva. Aquesta correlació està en línia amb la suggerència de Yang i colllegues (2013) que proposava un vincle entre el comportament dels estudiants 
al fòrum i l'abandonament dels estudis. Els resultats d'aquest treball confirmen que aquesta relació existeix i que, per tant, l'anàlisi del sentiment dels estudiants al fòrum pot ser un indicador que serveixi per a predir l'abandonament als estudis en línia. Així mateix, dels estudis fets per García Manga (2018) sobre l'abandonament dins de la mateixa tipologia de població, el resultat ha servit per a distingir una tendència més clara sobre quins són els factors que en determinen l'abandonament. El feedback als alumnes és un dels elements que s'ha mesurat dins de l'anàlisi del sentiment dels estudiants a les aules i aquest sí que ha resultat ser rellevant. En la mateixa línia, el resultat confirma de nou el que Gütl i collegues (2014) deien sobre el fet que la manca de retroalimentació i la poca interacció amb els companys podien provocar l'elevatíndex d'abandonament als MOOC.

\subsection{Implicacions pràctiques}

Dels resultats de la recerca se'n desprèn una possible millora pel que fa a la fidelització dels estudiants en un EVA. Aquesta es basaria en la possibilitat de què el tutor disposés d'una eina que li permetessin tenir informació actualitzada del seu estat emocional. La correlació mostrada entre l'anàlisi del sentiment i els resultats acadèmics confirma el fet que els estudiants reaccionen millor a una tutoria positiva que no pas a una de negativa i que, per tant, un coneixement a priori dels sentiments del grup-classe podria ser aplicat pel tutor per a rebaixar la taxa d'abandonament.

Un dels objectius secundaris del treball ha estat el desenvolupament d'una aplicació en Python per a I'anàlisi del sentiment dels textos expressats als fòrums de les aules. El treball de recerca s'ha fet ex post facto i, en conseqüència, no s'ha pogut intervenir en els resultats. Això no obstant, el codi de creació i entrenament de la màquina d'aprenentatge automàtic que ara ja existeix es podria utilitzar per a informar sobre l'estat emocional de l'aula amb una periodicitat determinada de forma que el tutor pogués intervenir al fòrum per a millorar la seva presència docent així com intentar canviar la tendència emocional del grup-classe. Per a fer-ho, el tutor hauria de convertir les intervencions del fòrum en arxius de text $\mathrm{i}$ introduir-los a la màquina per a conèixer la valència emocional resultant.

\subsection{Limitacions de la recerca}

L'estudi s'ha realitzat en un grup transversal format per tots els estudiants de cicles formatius de grau superior de l'Institut Obert de Catalunya. Les limitacions de la població són evidents. D'una banda, la recerca s'ha fet sobre les emocions expressades pels alumnes durant només un semestre. Concretament, el primer semestre del curs escolar entre els mesos de setembre i de febrer. No hi ha, per tant, espai per a quantificar la possible variabilitat estacional entre el primer semestre i el segon. Considerant que la majoria dels alumnes de l'IOC es matriculen de més d'una assignatura cada curs i que, en conseqüència, els mateixos estudiants han seguit la seva formació durant el segon semestre (de febrer a juny), no s'ha pogut analitzar quins canvis emocionals produeix la continuïtat de la formació sinó que s'ha mesurat tan sols el període post vacacional.

Les restriccions fruit de l'aplicació de la LOPD ens ha impedit també poder realitzar una descripció més acurada dels participants. Així, no s'ha pogut distingir entre els resultats per gènere, per edat, per antiguitat a l'entitat educativa, per nombre d'assignatures cursades simultàniament, etc. Òbviament, poder disposar d'aquesta informació hauria ajudat a perfilar més acuradament els resultats.

En un altre ordre de coses, la classificació prèvia dels missatges del fòrum en termes de textos positius i negatius ha estat realitzada pel mateix autor del treball. Aquest fet ha produït dues restriccions alhora. D'una banda, el biaix personal de la classificació que pot haver influït en la forma com la màquina hagi classificat els missatges objecte de l'estudi. De l'altra, la necessitat d'entrenar i testejar la màquina amb uns arxius obtinguts de la mateixa població perquè no existeix cap corpus de textos de sentiments d'un 
entorn educatiu i en català ha reduït les aules per a la recerca de les deu que es disposaven a només 6. Aquesta reducció ha provocat que la correlació s'hagi hagut de fer amb una població reduïda.

Finalment, les possibilitat del treball han limitat la seva extensió a dues polaritats emocionals binàries, fet que no ha permès tampoc expandir les característiques de la màquina d'aprenentatge automàtic ni en finesa (detecció de més d'un nivell per a cada emoció) ni en espectre emocional (incorporació de diferents emocions a l'anàlisi).

\subsection{Futures recerques}

De les limitacions exposades a l'apartat anterior, se'n determinen les línies de recerca futures. En primer lloc, caldria expandir l'anàlisi del sentiment a més d'un període lectiu de forma que es pogués observar si hi ha cap efecte estacional. A més, el fet de disposar de dades de major durada ens permetria també aprofundir en el concepte d'abandonament per a poder-lo mesurar amb més exactitud, sense haver-lo de limitar al comportament dels estudiants durant un semestre. Així mateix, poder optar a un període de temps més gran, també ens facilitaria l'augment de la població i, de retruc, en milloraria els resultats de la correlació.

En segon lloc, seria necessària la creació d'una màquina d'aprenentatge automàtic capaç de classificar diferents sentiments amb diferents valències. Aquesta major precisió serviria, d'una banda, per a facilitar al tutor l'estat emocional de forma més exacta que l'orientés millor sobre la forma i el sentit que hauria de prendre la seva participació al fòrum; de l'altra, ens ajudaria a reconèixer millor els factors reals que intervenen en la decisió d'abandonar els estudis.

Finalment, com a colofó de les dues línies de recerca anteriors, seria important poder realitzar l'anàlisi del sentiment tot marcant per un determinat sincronisme (per exemple, un cop cada més, a l'inici i al final de cada exercici d'avaluació contínua...) que ens permetés poder conèixer els canvis i els moviments sobre com responen els alumnes en diferents períodes dins d'un mateix semestre.

\section{Referències bibliogràfiques}

Altrabsheh, N., Gaber, M. M., \& Cocea, M. (2013). SA-E: Sentiment analysis for education. Frontiers in Artificial Intelligence and Applications, 255, 353-362. https://doi.org/10.3233/978-1-61499-264-6-353

Anderson, T. (2004). Teaching in an online learning context. Theory and Practice of Online Learning, 273.

Anderson, T., Rourke, L., Garrison, D. R., \& Archer, W. (2001). ASSESSING TEACHING PRESENCE IN A COMPUTER CONFERENCING CONTEXT. JALN (Vol. 5). Retrieved from http://citeseerx.ist.psu.edu/viewdoc/download?doi=10.1.1.95.9117\&rep=rep1\&type=pdf

Borges, F. (2005). La frustació de l'estudiant en línia: Causes i accions preventives. Digithum: Revista Digital d'Humanitats, 7, 3.

Conrad, D. L. (2002). Engagement, Excitement, Anxiety, and Fear: Learners' Experiences of Starting an Online Course. American Journal of Distance Education, 16(4), 205-226. https://doi.org/10.1207/S15389286AJDE1604_2

Consortium, T. N. M. (2017). Horizon Report 2017 Library Edition. NMC Horizon Report: 2017, Library Ed, 60. https://doi.org/http://cdn.nmc.org/media/2017-nmc-horizon-report-library-EN.pdf 
EUCASE Review. (2018). 2018 NMC Horizon Report | EDUCAUSE. Retrieved from https://library.educause.edu/resources/2018/8/2018-nmc-horizon-report

Ezen-Can, A., Boyer, K. E., Kellogg, S., \& Booth, S. (2015). Unsupervised modeling for understanding MOOC discussion forums. In Proceedings of the Fifth International Conference on Learning Analytics And Knowledge - LAK '15 (pp. 146-150). https://doi.org/10.1145/2723576.2723589

García-Mangas, P. (2018). Factors associats amb la persistència dels alumnes als estudis de formació professional online. Retrieved from http://hdl.handle.net/10609/77025

Garrison, D. Randy, M., \& Cleveland-Innes, M. (2005). Facilitating Cognitive Presence in Online Learning: Interaction Is Not Enough. American Journal of Distance Education, 19(3), 133-148. https://doi.org/10.1207/s15389286ajde1903_2

Garrison, D R. (2007). Online Community of Inquiry Review: Social, Cognitive, and Teaching Presence Issues. Retrieved from https://files.eric.ed.gov/fulltext/EJ842688.pdf

Gilly, S. (2000). E-Moderating: The Key to Teaching and Learning Online. London: Kogan Page.

Gütl, C., Rizzardini, R. H., Chang, V., \& Morales, M. (2014). Attrition in MOOC: Lessons Learned from DropOut Students. In Communications in Computer and Information Science (Vol. 446 CCIS, pp. 37-48). Springer, Cham. https://doi.org/10.1007/978-3-319-10671-7_4

Mckerlich, R., Riis, M., Anderson, T., \& Eastman, B. (2011). Student Perceptions of Teaching Presence, Social Presence, and Cognitive Presence in a Virtual World. MERLOT Journal of Online Learning and Teaching (Vol. 7). Retrieved from https://auspace.athabascau.ca/bitstream/handle/2149/3519/mckerlich_0911.pdf?sequence=1\&isAllow ed $=y$

Munezero, M., Montero, C. S., Mozgovoy, M., \& Sutinen, E. (2013). Exploiting sentiment analysis to track emotions in students' learning diaries. In Proceedings of the 13th Koli Calling International Conference on Computing Education Research - Koli Calling '13. https://doi.org/10.1145/2526968.2526984

Nielsen, F. A. (2011). A new ANEW: Evaluation of a word list for sentiment analysis in microblogs. In CEUR Workshop Proceedings. https://doi.org/10.1016/j.knosys.2015.06.015

Ortigosa, A., Martín, J. M., \& Carro, R. M. (2014). Sentiment analysis in Facebook and its application to elearning. Computers in Human Behavior. https://doi.org/10.1016/j.chb.2013.05.024

Pang, B., \& Lee, L. (2009). Opinion mining and sentiment analysis. Computational Linguistics. https://doi.org/10.1162/coli.2009.35.2.311

Pang, B., Lee, L., \& Vaithyanathan, S. (2002). Thumbs up? Sentiment Classification using Machine Learning Techniques. Proceedings of the Conference on Empirical Methods in Natural Language Processing (EMNLP), 79-86. https://doi.org/10.3115/1118693.1118704

Pritchard, M. E., \& Wilson, G. S. (2003). Using Emotional and Social Factors to Predict Student Success. Journal of College Student Development, 44(1), 18-28. https://doi.org/10.1353/csd.2003.0008

Resonance, P., Anatase, I. T., Livraghi, S., Chiesa, M., Paganini, M. C., \& Giamello, E. (1830). On the Nature of Reduced States in Titanium Dioxide as Monitored by Electron. JALN, 2(Cvd), 1-2. Retrieved from 
https://auspace.athabascau.ca/bitstream/handle/2149/725/assessing_teaching_presence.pdf?sequence $=1 \&$ isAllowed $=\mathrm{y}$

Rodríguez-Gómez, D., Feixas, M., Gairín, J., \& Luís Muñoz, J. (2012). Understanding Catalan University dropout from a comparative approach. Procedia-Social and Behavioral Sciences, 46, 1424-1429. https://doi.org/10.1016/j.sbspro.2012.05.314

Turney, P. D. (2001). Thumbs up or thumbs down? In Proceedings of the 40th Annual Meeting on Association for Computational Linguistics - ACL '02 (p. 417). https://doi.org/10.3115/1073083.1073153

Yanagimoto, H., Shimada, M., \& Yoshimura, A. (2013). Document similarity estimation for sentiment analysis using neural network. 2013 IEEE/ACIS 12th International Conference on Computer and Information Science (ICIS), 105-110. https://doi.org/10.1109/ICIS.2013.6607825

Yang, D., Sinha, T., Adamson, D., \& Rosé, C. P. (2013). "Turn on, Tune in, Drop out": Anticipating student dropouts in Massive Open Online Courses. In Proceedings of the 2013 NIPS Data-driven education workshop (Vol. 11, pp. 1-8). https://doi.org/10.1016/0027-5107(86)90134-X 


\section{ANNEXOS}

\section{HTML2TXT.PY}

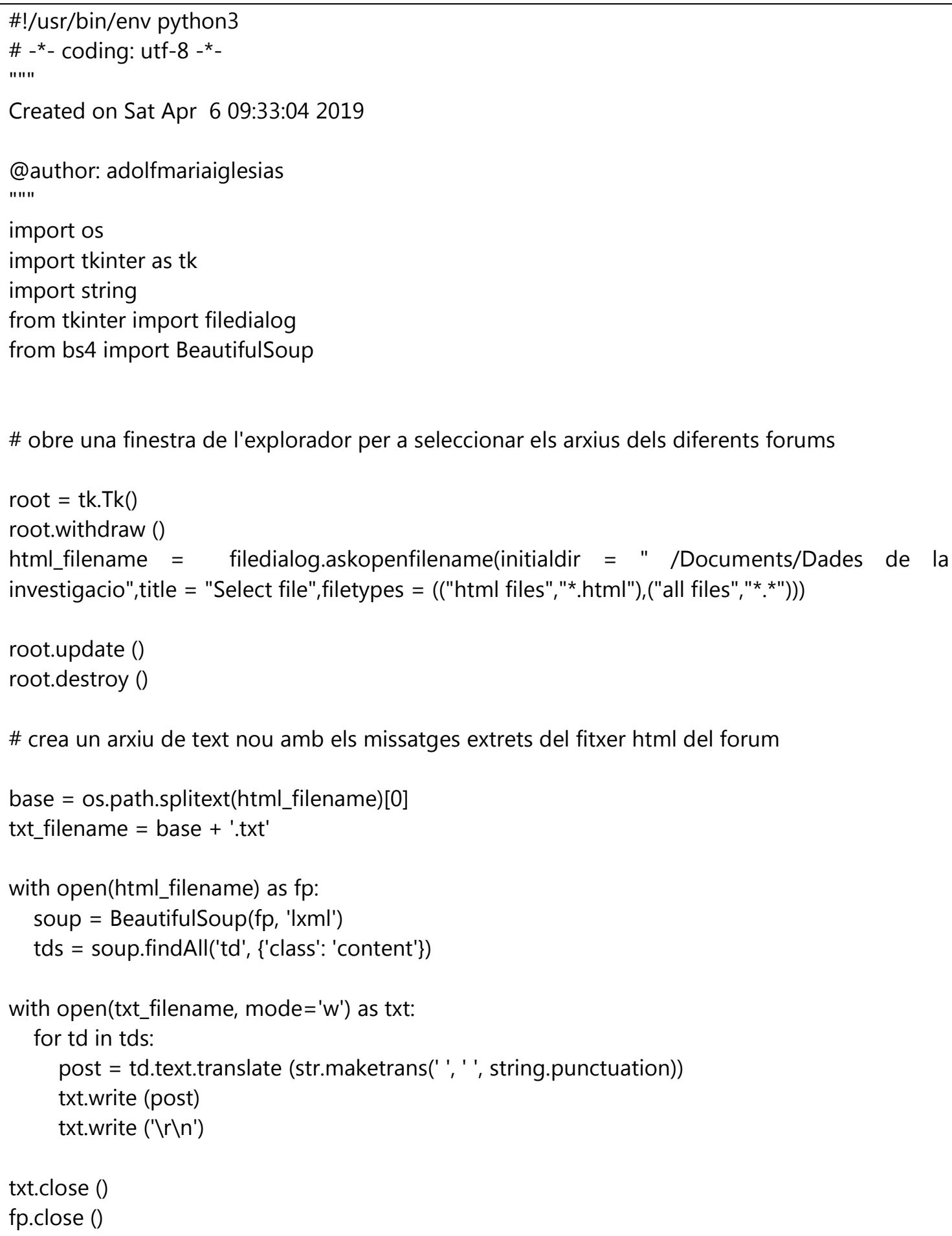

